\title{
An FPGA based Regenerative Braking System of Electric Vehicle Driven by BLDC Motor
}

\author{
R. Elavarasi ${ }^{*}$ and P. K. SenthilKumar ${ }^{2}$ \\ 'Department of EEEM, AMET University, Chennai, India; elavarasi_rr@yahoo.com \\ 2Department of ICE, SRM University, Chennai, India; pksenthil2007@yahoo.co.in
}

\begin{abstract}
BLDC motor is a rotating synchronous machine. BLDC motors are electronically commutated. This paper discusses digital pulse width modulation control implemented in FPGA for a BLDC drive in both motoring and generating modes of operation with Regenerative Braking System (RBS). Regenerative braking can improve energy usage efficiency and can prolong the driving distance of Electric Vehicles (EVs). The proposed system includes BLDC motor control utilizing the traditional PID control, and the distribution of braking force adopts fuzzy logic control. RBS has the ability to recover energy and ensure the safety of braking. The implementation of digital pulse width modulation control using FPGA results in a considerable reduction of size and the cost of the system.
\end{abstract}

Keywords: BLDC Motors, Field Programmable Gate Array (FPGA), Proportional Integral Derivative (PID), Regenerative Braking System (RBS)

\section{Introduction}

In Recent years, the invention of regenerative braking in Electric Vehicles (EVs) improves the efficiently of electric vehicle. Regenerative braking system provides energy to the battery while braking occurs.

BLDC motor consists of two parts like an induction motor. Stator Windings may be connected in star $(\mathrm{Y})$ or delta $(\Delta)$. The $\mathrm{Y}$ connected winding pattern gives high torque at low RPM and the $\Delta$ connected winding pattern gives low torque at low RPM.

BLDC $^{1,2}$ motors have high dynamic response, low inertia and high efficiency and also it has good speedtorque characteristics, high reliability due to electronic commutation. Polarity reversal is achieved by power transistors which are switched in synchronism with the rotor position.

An FPGA controller has been implemented for a BLDC motor. With the introduction of digital controller, the BLDC system has only two levels of operation such as low duty level $\left(\mathrm{D}_{\mathrm{L}}\right)$ and high duty level $\left(\mathrm{D}_{\mathrm{H}}\right)$. Digital controllers reduce the cost and provide ease of operation.

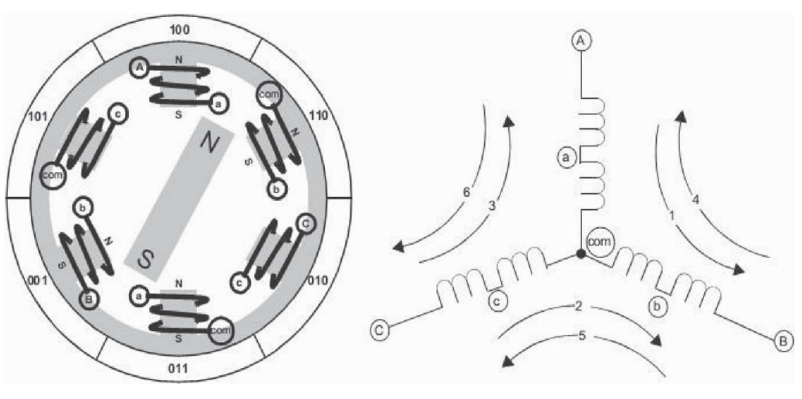

Figure 1. Y-connected BLDC motor.

\section{Motor and Control}

\subsection{BLDC Motors}

BLDC motor is a rotating synchronous machine. The stator and rotor magnetic fields are rotating at same fre-

*Author for correspondence 
quency. As shown in Figure 1, the stator is made up of laminated steel stacked to carry the stator windings and the rotor has permanent magnets. The number of poles on the rotor depends upon the application. In BLDC motors, the brushes and commutator arrangement is replaced by a Power Electronic converter.

\subsection{Control Circuitry}

In Power Electronic Converter as shown in Figure 2, two switches are conducting at any instant of time. One switch is from upper side and one from lower side of the bridge. For a star connected system, only two phases are connected to the input and the third phase is left free. Each phase is conducting for a period of $120^{\circ}$ electrical during flat portion of back EMF. For a period of $60^{\circ}$ electrical commutation event occurs between phases as shown in Figure 3. The details pertaining to rotor position are needed for proper commutation. By using Hall effect sensors, the position of rotor can be directly detected by observing back EMF of open phase ${ }^{3}$.

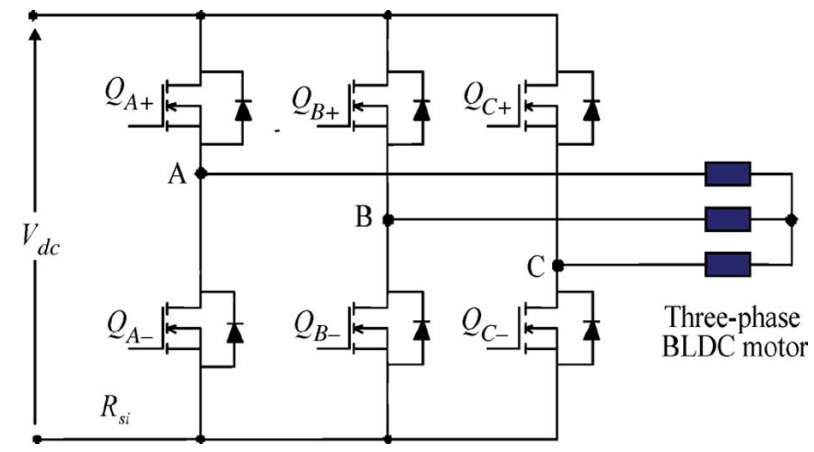

Figure 2. Typical Inverter drive system for a BLDC motor.

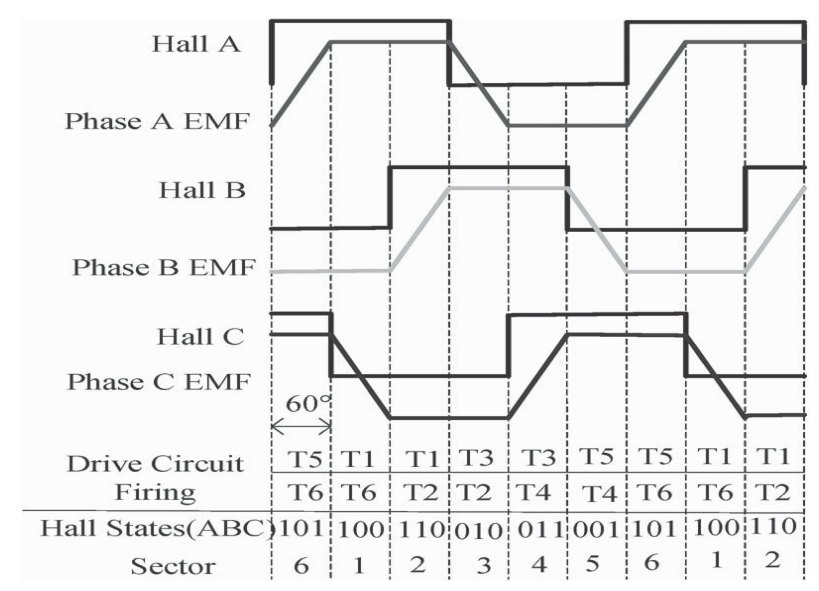

Figure 3. Back EMF and phase current variation.
BLDC motors are electronically commutated. The stator windings of a BLDC motors should be energized in a cycle. The knowledge of rotor position is required to track the proper energizing cycle. The Hall effect sensors detect the position of rotor. The Hall effect sensors are mounted on the stator4. From the observation of Hall Effect sensors, we can get a 3-b code with values ranging from one to six. The present location of rotor in a sector can be identified by this code. Appropriate exciting sequence for rotor rotation is obtained by each code value. In Hall Effect sensors, the invalid states are state " 0 " and state "7". The logic levels of sensors are such that sensor $\mathrm{C}$ represents the most significant bit (MSB) and sensor A gives the least significant bit (LSB). The state table gives the details of inputs to the sensors and the equivalent drive state necessary for commutation.

\section{Digital PWM Control of BLDC Drives.}

In a BLDC Speed control can be done by changing the applied motor phase voltages ${ }^{5,6}$. To change the motor phase voltages, pulse width modulation, PWM, or hysteresis control ${ }^{7,8}$ can be employed. A new fixed frequency digital pulse width modulation controller has been implemented, simulated and experimentally verified for BLDC motor. The introduction of digital controller in BLDC digital system, the speed can be regulated by two levels of operation such as low duty level $\left(\mathrm{D}_{\mathrm{L}}\right)$ and high duty level $\left(D_{H}\right)$. Figure 4 explains the rules of the digital controller. The digitals controller does not require any state observer. Figure 5 shows the functional blocks of digital PWM controller for BLDC motor.

\section{EV Modelinglogy}

\subsection{Driver Subsystem-Regenerative Braking}

The driver block delivers the desired drive torque and the desired brake torque through the activation of the accelerator and brake pedal, respectively. If the driver wishes to accelerate the vehicle, he depresses the accelerator. Depending on the amount of depression of the accelerator pedal, a driver torque request is sent to corresponding the vehicle through various power train systems such as the battery and motor models. The regeneration starts only when the brake pedal is pressed. Once the brake 


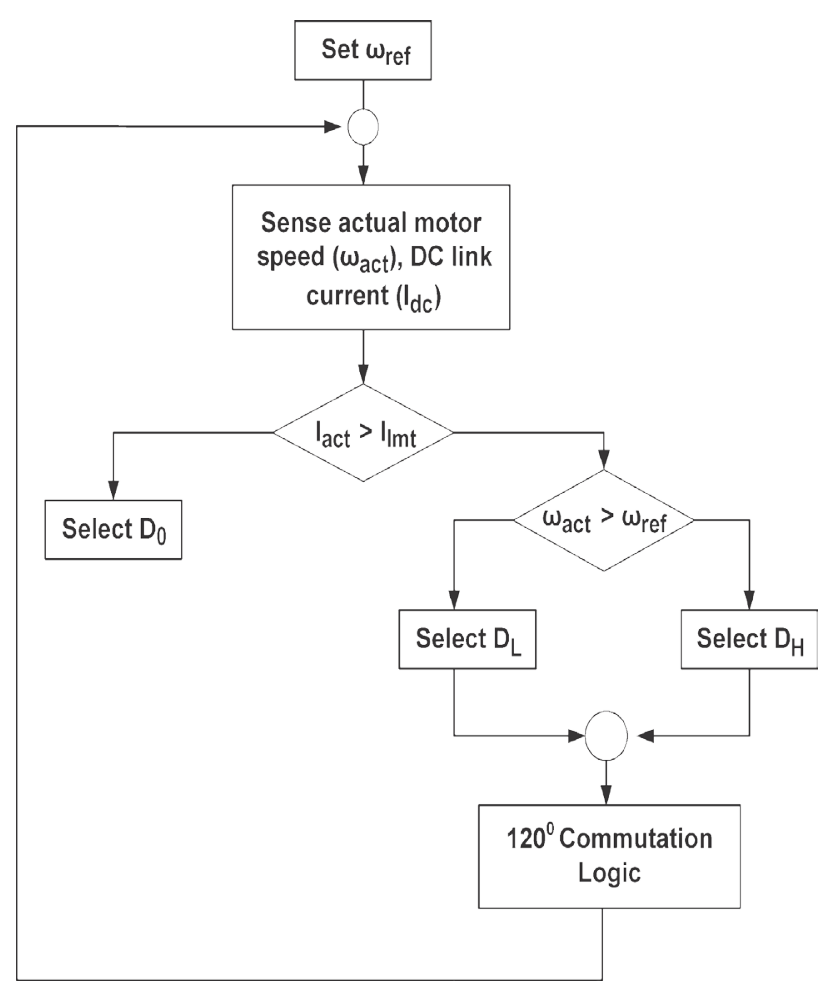

Figure 4. Flowchart of novel digital control.

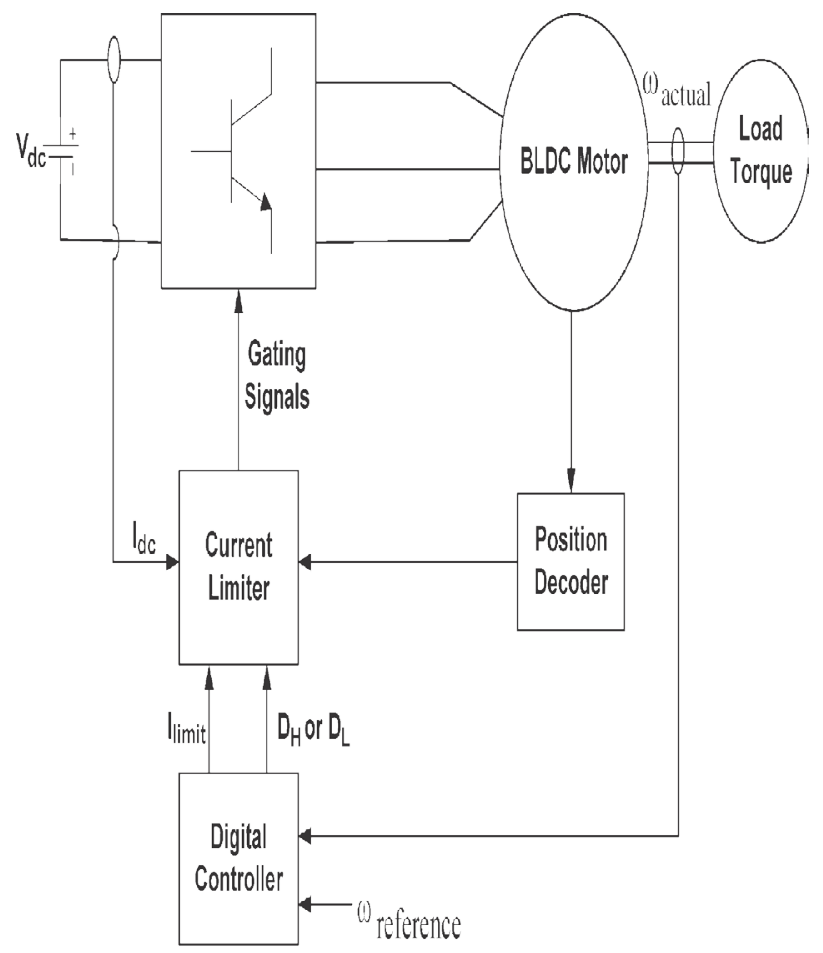

Figure 5. Block diagram of digital PWM control for BLDC motor. pedal is depressed, in accordance with the position of the brake pedal, a corresponding proportion of brake torque is applied. The power from the battery drives the electric machine (EM). The EM works as a motor to propel the vehicle when positive power is fed in and as a generator when negative power is fed in.

\subsection{Field-Programmable Gate Arrays (FPGAs)}

An FPGA platform used for controlling the BLDC machine is Spartan 3/Xilinx. Reference speed value was set digitally, and a speed loop was used to compare the actual speed and the reference speed and based on error to determine the duty cycle for the next period. The actual speed was easily calculated as a time between two Hall effect signals. The schematic of the controller simulated in the FPGA is shown in Figure 6. Inputs to the FPGA device include three Hall effect sensors and reference speed information, while output signals are triggers for switching on and off of IGBTs. In addition, the dc-link current was measured using LEM transducer, and analog signal is sent first to A/D converter, and then to FPGA, for current protection. In order to show the speed error, 8-b D/A (digital-to-analog) converter was used.

\subsection{Fuzzy Control}

The fuzzy logic control strategy for EV braking force distribution can be easily demonstrated by the influence of different factors. Therefore, the fuzzy control theory is applied to the EV braking force distribution. The three inputs are the EV front-wheel braking force, speed, and battery charge state [state of charge (SOC). The output variable is the ratio which is proportional to the regenerative braking force taking in the front braking force. The value of the braking force represents the braking distance and time the driver requires. We prefer the concourse of speed to be low, middle, and high, and the universe of discourse is 0, 2000 as shown in Figure 7 SOC: when the battery's SOC is less than $10 \%$, the internal resistance of the battery is high, unsuitable charging in this case; the regenerative braking force should be a smaller proportion. When the SOC is between $10 \%$ and $90 \%$, the battery can be charging with a large current; the ratio of the regenerative braking force should be correspondingly increased. When the SOC is greater than $90 \%$, the charging current should be lower. 


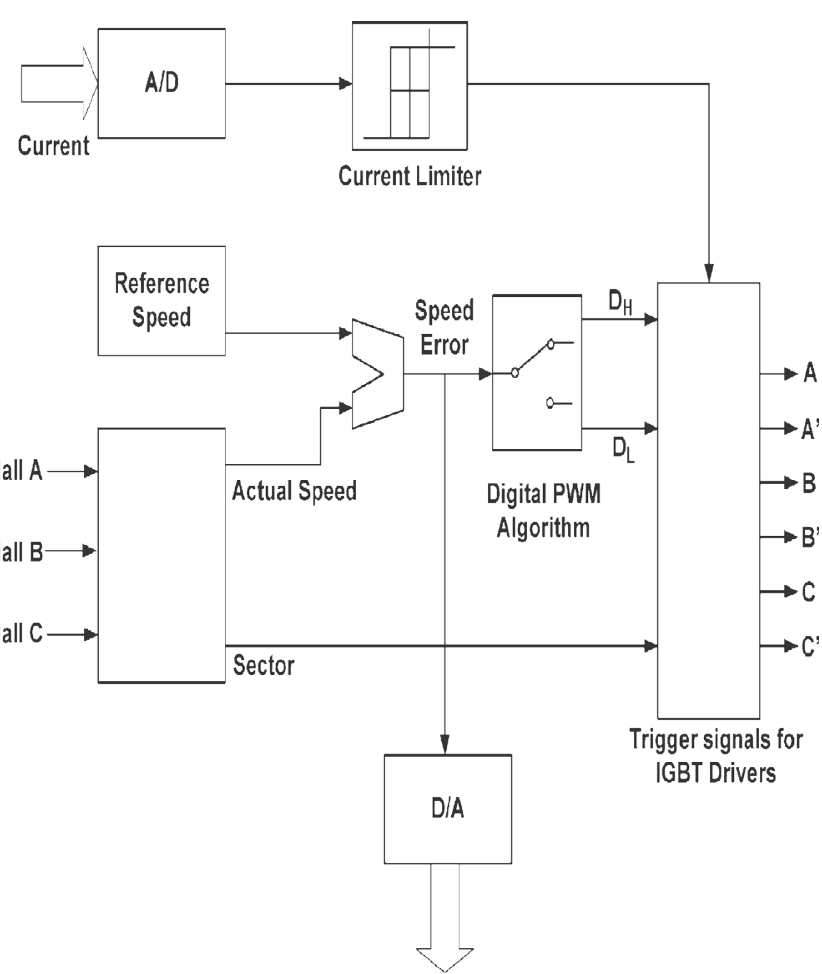

Figure 6. Block diagram showing operations and functions implemented in FPGA device..

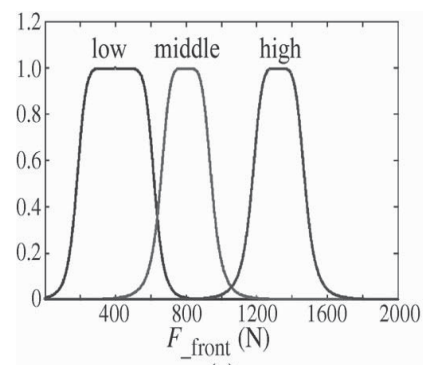

(a)

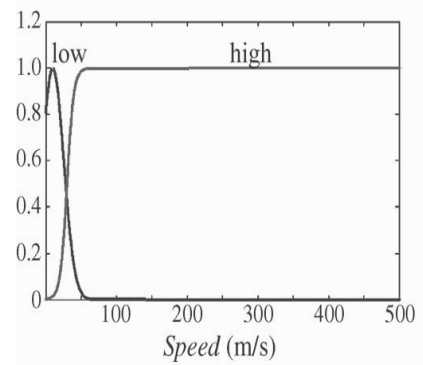

(c)

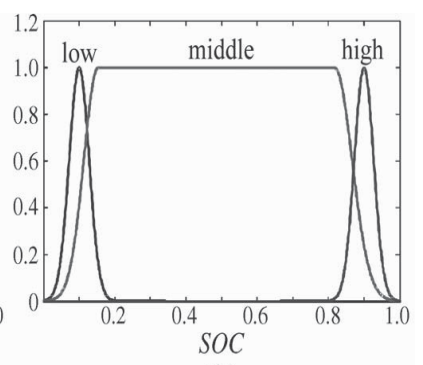

(b)

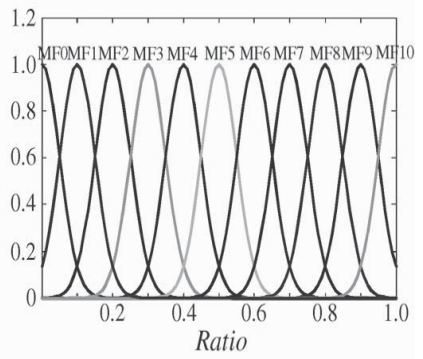

(d)
Figure 7. Membership functions of fuzzy control.

(a) Membership function of the front braking force. (b) Membership function of the SOC. (c) Membership function of speed. (d) Membership function of ratio.

\subsection{Proportional-Integral Derivative (PID) Control}

With PID control used primarily to ensure a constant brake torque, different braking force values will give different PWMs. It is supposed that PID control can quickly adjust the desired PWM in order to maintain braking torque constantly. A constant electrical braking torque can be achieved during the fuzzy inference. In real-time, PID control can be used to control the braking torque.

\section{Simulation and Result}

The Regenerative braking system of BLDC motor drive system with digital controller was implemented and simulated using MATLAB and Simulink. The test is performed according to urban driving schedules. The simulation results are represented as follows.

\subsection{Performance and Force Distribution at Different Brake Pedal Inputs}

At different braking scenarios, we simulated the dynamic performance of the car and force distribution due to different brake pedal inputs.

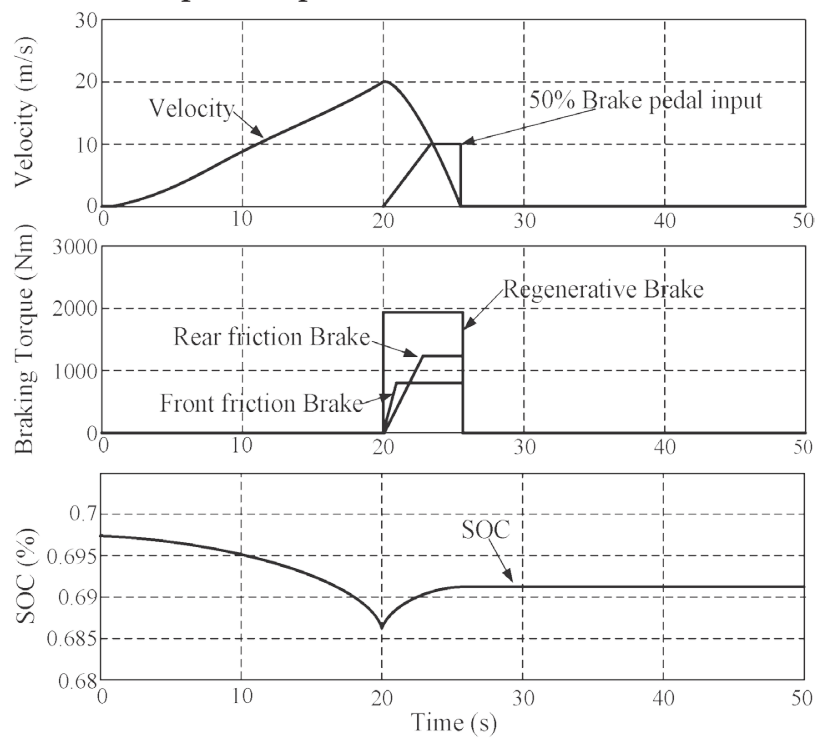

Figure 8. Simulation EV speed curve for $50 \%$ brake.

\subsection{Energy Recovery Efficiency}

As shown in Figure 9, the shadow part is the recover energy whose ratio is about $50 \%$. However, the ratio is 
related to the EV speed, traffic information, SOC, and driver's habits closely.

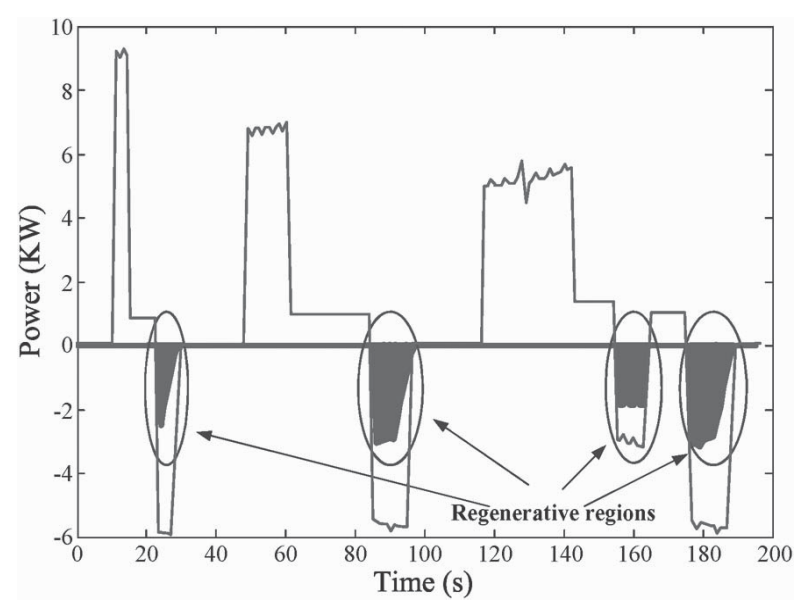

Figure 9. Energy regeneration.

\section{Conclusion}

A new digital FPGA control concept for BLDC machines has been introduced. Speed regulation is achieved by alternating between low duty and high duty. Under dynamic load conditions, the proposed controller is capable of regulating speeds without the use of an observer. We have adopted PID control to adjust the BLDC motor PWM duty to obtain the constant brake torque. PID control is faster than fuzzy control, so the two methods combined together can realize the smooth transitions. Results are obtained using MATLAB and Simulink. Control schemes with a DSP, the cost may be as much as 20 dollars. The novel digital PWM control scheme uses few components. In mass production, an analog IC implemented using the aforementioned elements would cost less than a dollar, which would make the BLDC motors affordable. Therefore, it can be concluded that this RBS has the ability to recover energy and ensure the safety of braking. In future, we can incorporate renewable energy sources with RBS in electric vehicle.ler is capable of regulating speeds without the use of an observer. We have adopted PID control to adjust the BLDC motor PWM duty to obtain the constant brake torque. PID control is faster than fuzzy control, so the two methods combined together can realize the smooth transitions. Results are obtained using MATLAB and Simulink. Control schemes with a DSP, the cost may be as much as 20 dollars. The novel digital PWM control scheme uses few components. In mass production, an analog IC implemented using the aforementioned elements would cost less than a dollar, which would make the BLDC motors affordable. Therefore, it can be concluded that this RBS has the ability to recover energy and ensure the safety of braking. In future, we can incorporate renewable energy sources with RBS in electric vehicle.

\section{References}

1. Mutoh N, Nakano Y. Dynamics of front-and rear wheel independent drive type electric vehicles at the time of failure. IEEE Trans Ind Electron. 2012 Mar; 59(3):1488-99.

2. Botanic E, Neuschl Z, Plikat R. No-load performance analysis of brushless Dc machines with axially displaceable rotor. IEEE Trans Ind Electron. 2014 Apr; 61(4):1692-99.

3. Chen Z, Tomita M, Doki S, Okuma S. New adaptive sliding observers for position and velocity sensorless controls of brushless Dc motors. IEEE Trans Ind Electron. 2000 Jun; 47(3):582-91.

4. Yedamale P. Brushless DC (BLDC) motor fundamentals, application notes-microchip. AN885.

5. Pillay P, Krishnan R. Modeling of permanent magnet motor drives. IEEE Trans Ind Electron. 1988 Nov; 35(4):537-41.

6. Pillay P, Krishnan R. Modeling, simulation and analysis of permanent-magnet motor drives ii. the brushless dc motor drive. IEEE Trans Ind Appl. 1989 Mar/Apr; 25(2):274-9.

7. Tomita M, Senjyu T, Doki S and Okuma S. New sensor less control for brushless dc motors using disturbance observers and adaptive velocity estimations. IEEE Trans Ind Electron. 1998 Apr; 45(2):274-82

8. Aboulnaga AA, Desai PC, Rodriguez F, Cooke TR and Emadi A. A Novel Low-Cost High-Performance SinglePhase Adjustable-Speed Motor Drive Using Pm Brushless Dc Machines: IIT's Design For 2003 Future Energy Challenge. Proc 19th Annu IEEE Appl Power Electron Conference; 2004 Feb; Anaheim. p. 1595-603. 